\title{
Adjuvant Sufentanil Decreased the EC50 of Epidural Ropivacaine for Labor Analgesia in Healthy Term Pregnancy
}

\author{
Bo Xiang' \\ Jian Yang ${ }^{2}$ \\ Xiaofeng Lei' \\ Jin $\mathrm{Yu} \mathbb{D}^{1}$
}

'Department of Anesthesiology, Chongqing Health Center for Women and Children, Chongqing, 40I I47, People's Republic of China; ${ }^{2}$ Department of Anesthesiology, Chongqing Dongnan Hospital, Chongqing, 40I336, People's Republic of China
Correspondence: Jin Yu

Department of Anesthesiology, Chongqing Health Center for Women and Children, No. 120, Longshan Road, Yubei District, Chongqing, 40II47,

People's Republic of China

Tel +86-18623II 7820

Fax +86-23-63702844

Email dodoes@qq.com

Jian Yang

Department of Anesthesiology,

Chongqing Dongnan Hospital, No. 98,

Tongjiang Ave, Nanan District, Chongqing,

401336, People's Republic of China

Tel/Fax +86-23-62905685

Email charlalice@sina.com
Objective: The optimal concentration of ropivacaine as epidural labor analgesia combined with sufentanil has not been established. This study aimed to determine the median effective concentration (EC50) of epidural ropivacaine for labor analgesia in healthy term pregnancy when co-administered with sufentanil as an adjuvant or alone.

Patients and Methods: Sixty healthy parturients scheduled for epidural labor analgesia were enrolled in the study. They were divided into a saline group (Group C) and an epidural sufentanil $(0.5 \mu \mathrm{g} / \mathrm{mL})$ group (Group S). The initial concentration of ropivacaine was set at $0.125 \%$, which was then varied by $0.01 \%$ using the up-and-down sequential allocation method. The hemodynamics were continuously monitored during delivery. A visual analog scale was used to evaluate the degree of pain. The Ramsay sedation score, duration of the labor stages, the onset of epidural analgesia, and adverse effects were recorded. Neonatal outcomes were evaluated using the Apgar scores and umbilical artery blood gas analysis.

Results: The EC50 of ropivacaine was $0.085 \%$ (95\% CI, $0.079-0.090 \%$ ) in Group S and $0.109 \%(95 \%$ CI, $0.105-0.112 \%)$ in Group C. The EC95 of ropivacaine was $0.096 \%$ (95\% CI, $0.090-0.118 \%)$ in Group S, and 0.116\% (95\% CI, 0.113-0.127\%) in Group C. The difference between the groups was statistically significant $(\mathrm{p}<0.001)$. The stable hemodynamics, satisfactory analgesia, and good neonatal outcomes were comparable in both groups $(\mathrm{P}>0.05)$. Conclusion: The EC50 of ropivacaine was reduced by $22 \%$ when co-administered with sufentanil for epidural labor analgesia in primipara. (www.chictr.org.cn; registration number: ChiCTR2000039547).

Keywords: median effective concentration, ropivacaine, sufentanil, labor analgesia

\section{Introduction}

With the recent advances in modern medicine and comfort care, analgesia in labor is increasingly applied in obstetrics. Epidural analgesia for labor is a popular and effective technique because of its reliable performance and quick onset. It works in $95 \%$ of the cases by adjusting the anesthetic concentration according to the parturient's condition. ${ }^{1,2}$ Opioids such as morphine, fentanyl, and sufentanil combined with ropivacaine are commonly used for regional anesthesia to improve the anesthetic effects and reduce the local intrathecal dosage. ${ }^{3,4}$

Sufentanil, a synthetic opioid, has a favorable analgesic effect and fewer adverse reactions. It has been recommended as an adjuvant with ropivacaine $(0.0625-0.15 \%)$ for an epidural in the latest expert consensus on epidural labor analgesia. Previous studies demonstrated that sufentanil $(0.5 \mu \mathrm{g} / \mathrm{mL})$ with ropivacaine for labor analgesia 
could reduce local anesthetic requirements and minimize motor block. ${ }^{5-8}$ However, the optimal dose of ropivacaine can be reduced by sufentanil $(0.5 \mu \mathrm{g} / \mathrm{mL})$ is not clear due to the variety of administration methods.

Therefore, the present study was designed to determine the median effective concentration (EC50) of epidural ropivacaine for labor analgesia in healthy term pregnancy when co-administered with sufentanil adjuvant or alone using the up-down sequential allocation technology.

\section{Methods}

\section{Study Design}

The study was implemented in accordance with the Declaration of Helsinki and was approved by the Research Ethics Committee of Chongqing Health Center for Women and Children (Number.2020-017). Written informed consent was obtained from all participants. This study was registered with the Chinese Clinical Trial Registry (ChiCTR) (www. chictr.org) (registration ID: ChiCTR2000039547).

Sixty full-term pregnant women scheduled for vaginal delivery with epidural labor analgesia were enrolled in the study. The inclusion criteria were: (1) 20-35 years old parturient women at 38-42 weeks of single pregnancy; (2) no abortion history; (3) categorized as Anesthesiologists physical status classification of American Society II (ASA II); and (4) normal coagulation function and platelet count. The exclusion criteria were: (1) cesarean section or labor induction; (2) contraindications to epidural anesthesia; (3) complications associated with important organs (heart, lung, kidney, and liver); (4) severe preeclampsia or malignant tumor; (5) history of lower abdominal surgery; (6) history of long-term sedatives or analgesics; and (7) a history of mental illness.

The enrolled parturients were allocated into Group $\mathrm{C}$ (epidural administration of ropivacaine with normal saline) or Group S (epidural administration of ropivacaine combined with sufentanil $(0.5 \mu \mathrm{g} / \mathrm{mL}))$ using the random number table method. The group allocation was done by Xiaofeng Lei, who was not involved in data collection and patient management. Sufentanil dissolved in citrate (sufentanil citrate injection, $1 \mathrm{~mL}: 50 \mu \mathrm{g}$, Ren Fu Shu Fen, lot No. 91A10071) is preservative-free with no additives or chemical stabilizers. Study participants and investigators who assessed the outcomes were blinded to the group details.

\section{Anesthetic Procedure}

Venous access was established (left upper limb) in the delivery room. Heart rate, blood pressure, and pulse oxygen saturation
$\left(\mathrm{SpO}_{2}\right)$ were monitored routinely (every 5 mins). The fetal heart rate was monitored using a Doppler. When cervical dilatation was $2 \mathrm{~cm}$, epidural analgesia was administered in the L2-3 interspace with an 18-gauge Tuohy needle in the left lateral position. An enhanced epidural catheter was inserted into the epidural space for $3-4 \mathrm{~cm}$. A test dose of $1 \%$ lidocaine $(3 \mathrm{~mL})$ was administered once the negative aspiration test for blood and cerebrospinal fluid was confirmed. After positioning the parturient in the supine position, the study solution was administered as a single bolus. The study solution $(8 \mathrm{~mL})$, previously prepared by the same anesthesia nurse, contained ropivacaine as the loading dose with or without sufentanil $(0.5 \mu \mathrm{g} / \mathrm{mL})$. The mixed solution was infused continuously at $10 \mathrm{~mL} / \mathrm{h}$ using a patient-controlled analgesia pump (PCA100B, Zhejiang Chenhe Medical Devices, China). The parturient was trained to use the pump for bolus dose on demand [visual analog scale (VAS) score > 7]. The pump model was set at a single bolus of $1.5 \mathrm{~mL}$ and lockout for $15 \mathrm{~min}$. The first labor stage duration was defined as the time from epidural administration to $10 \mathrm{~cm}$ cervical dilatation. Analgesia onset time was defined as the duration from epidural administration to a VAS score of $<3$.

Dixon sequential method was used in this experiment. ${ }^{9}$ The first parturient in each group received $0.125 \%$ ropivacaine combined with normal saline or sufentanil. The concentration of ropivacaine for the following parturient was determined using the up-down allocation methodology. ${ }^{10,11}$ Parturients were asked to report their pain on a standard VAS $30 \mathrm{~min}$ after administering the study solution. A VAS score $\leq 3$ was defined as effective analgesia. Based on the analgesic efficacy in the first patient, ropivacaine concentration for the next parturient was decreased or increased by $0.01 \%$. When a parturient reported effective analgesia, the subsequent parturient received a $0.01 \%$ lower dose of ropivacaine. On the other hand, when a parturient reported ineffective analgesia, the ropivacaine dose was increased by $0.01 \%$ for the next one. For the parturients who reported ineffective analgesia at $30 \mathrm{~min}$ after administration, an additional $10 \mathrm{~mL}$ of $1 \%$ lidocaine was epidural administered as rescue. Ineffective analgesia after the rescue bolus, indicating a problem in the epidural catheter's position, and this parturient's data were excluded from the study analysis. The next parturient received the same concentration as the excluded one. The continuous infusion was stopped when the baby was delivered. Procedure and epidural administration for all parturients were performed by the same anesthesiologist. 


\section{Outcome Measures}

Pain intensity was measured using VAS, ranging from $0-10$ as follows: 0 , no pain; $1-3$, mild pain; $4-6$, moderate pain; and 7-10, unbearable pain. A modified Bromage scale was used to assess motor block induced by intravertebral anesthesia: 0 , no motor block; 1 , inability to raise an extended leg but able to move knees and feet; 2 , inability to raise an extended leg and move knee but able to move feet; and 3, complete block of the motor limb. ${ }^{12}$ The onset of epidural analgesia, the duration of the first and second labor stages, umbilical artery $\mathrm{pH}, \mathrm{PaO}_{2}$ and $\mathrm{PaCO}_{2}$ immediately after delivery, and neonatal Apgar scores at 1, 5, and $10 \mathrm{~min}$ after birth were all recorded. An Apgar score less than 8 was defined as asphyxia. ${ }^{13}$

\section{Adverse Reactions}

A $20 \%$ decrease in the noninvasive mean arterial pressure compared to baseline was defined as hypotension. Respiratory depression was defined as $\mathrm{SpO}_{2} \leq 90 \%$ when the inhaled oxygen or respiratory rate was $<10$ breaths per minute. A heart rate (HR) lower than 60 beats per minute was defined as bradycardia, and the inability to urinate with a full bladder was defined as urinary retention. Itching, nausea, and vomiting were also assessed and recorded.

\section{Statistical Analysis}

We included 30 parturient women in each group. This sample size was sufficient when six pairs of sequence reversals were obtained to estimate the EC50 based on the up-down allocation method. ${ }^{14}$ The EC50, EC95, and 95\% confidence intervals (CIs) of ropivacaine were calculated using the probit method (probability unit regression) by analyzing the tallied numbers of "effective" and "ineffective" responses for each group. The EC50 of epidural ropivacaine was determined by calculating the mean values of the midpoints of pairs in parturients where an inadequate response was followed by an effective response (crossover), as previously described. ${ }^{10,11,14}$ The Student's $t$-test was used for comparing the EC50s. Overlapping CI methodology was used to test the differences in CIs for the EC50 values between the two groups. The difference was considered statistically significant when $83 \%$ of CIs did not overlap. ${ }^{15}$

Categorical variables are presented as numbers, and demographic measurement data as mean \pm standard deviation (SD). The normal distribution was statistically analyzed using the Kolmogorov-Smirnov test and normally distributed continuous variables were analyzed using $t$-test. Discrete variables were analyzed using the chi- square test. SPSS Statistics was used for data analysis. Statistical significance was defined as $p<0.05$.

\section{Results}

Figure 1 shows the research flow diagram. Three women who had a prolonged first labor stage and switched to cesarean section were withdrawn from the study. Finally, 60 parturients were included in the analysis. The demographic characteristics of the parturients in the two groups are presented in Table 1. The age, weight, height, body mass index, and gestational weeks in the two groups were similar $(P>0.05)$.

No motor block occurred in either group. The Bromage scores were all below 1 during labor, and the maximum sensory block level was around T10. The incidence of side effects (hypotension, respiratory depression, maternal bradycardia, itching, nausea, vomiting, and urinary retention) in the two groups was comparable $(P>0.05)$ (Table 2$)$.

The sequential concentrations of epidural ropivacaine with or without sufentanil are shown in Figures 2 and 3. The EC50 values of ropivacaine calculated using probit regression were $0.085 \%$ (95\% CI, 0.079-0.090\%) in Group S and 0.109\% (95\% CI, 0.105-0.112\%) in Group C. The EC95 values of ropivacaine were $0.096 \%$ (95\% CI, $0.090-0.118 \%$ ) in Group $\mathrm{S}$, and $0.116 \%(95 \% \mathrm{CI}, 0.113-0.127 \%)$ in Group C. The EC50 values for ropivacaine calculated by the mean values of the crossover's midpoints were 0.0887 in Group $\mathrm{S}$ and 0.111 in Group C. A significant difference was seen between the two groups $(P<0.001)$.

The time of analgesia onset, duration of the first and second stages of labor, umbilical artery $\mathrm{pH}, \mathrm{PaO}_{2}$, and $\mathrm{PaCO}_{2}$ immediately after delivery were comparable between the two groups $(P>0.05)$. The Apgar scores at 1,5 , and $10 \mathrm{~min}$ in neonates were not significantly different between the two groups. No neonatal asphyxia occurred in either of the groups (Table 3). The parturient self-control evaluation and satisfaction with the labor analgesia process was significantly higher in group $\mathrm{S}$ than group $\mathrm{C}(P<0.05)$.

\section{Discussion}

In this prospective, randomized up-down sequential allocation study, we found that the EC50 for epidural ropivacaine, when administered with or without sufentanil (0.5 $\mu \mathrm{g} / \mathrm{mL}$, as an adjuvant), was $0.085 \%$ and $0.109 \%$ respectively. Epidural infusion with sufentanil decreased the EC50 of ropivacaine by $22 \%$. 


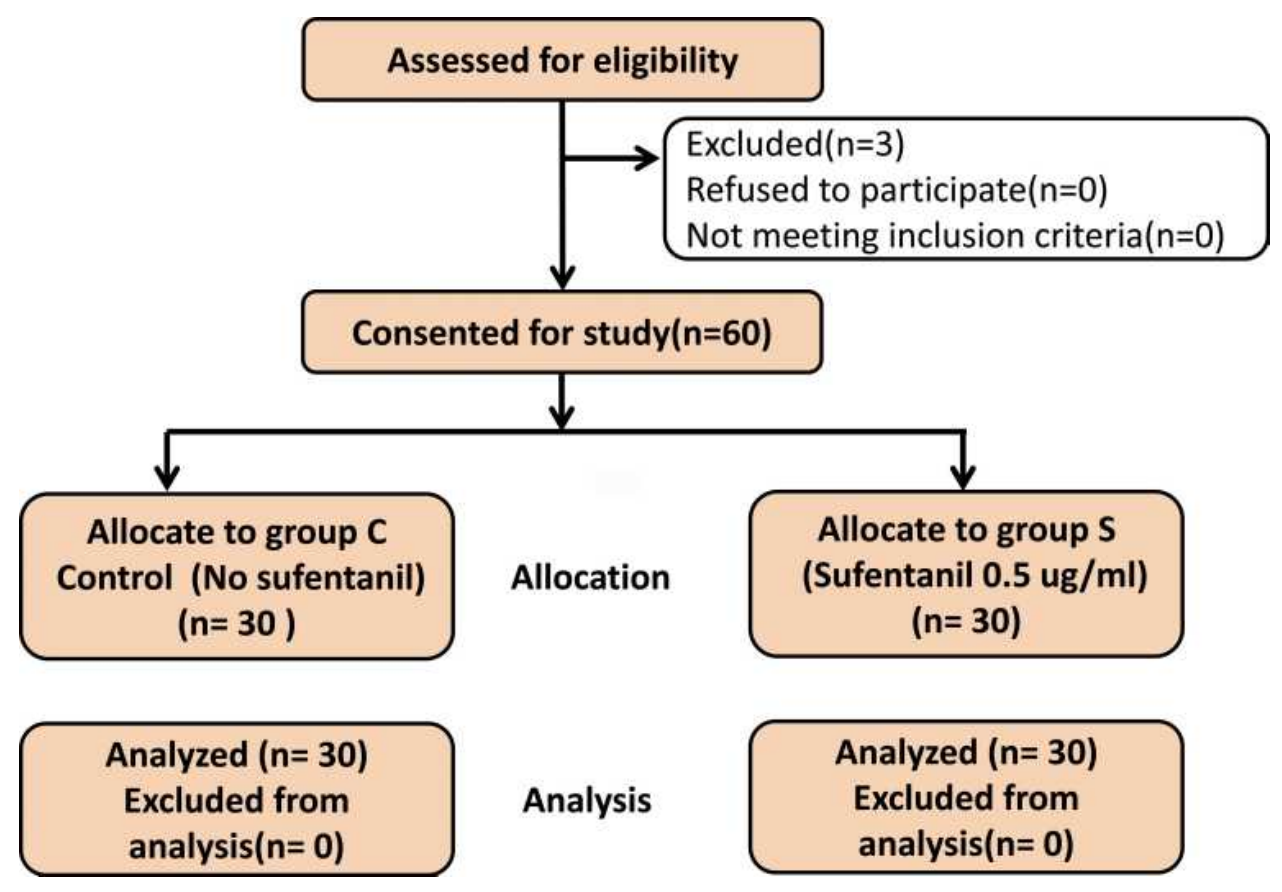

Figure I Flow diagram of study.

The best epidural labor analgesia should provide satisfactory analgesic effects with minimal side effects in both parturients and neonates. Adjuvant drugs such as morphine, fentanyl, and sufentanil are often used with local anesthetics to improve anesthesia quality and reduce the local anesthetic dosage. However, opioids may cause adverse effects as nausea, lethargy, and itching. ${ }^{3,4}$ Sufentanil is the most frequently used adjuvant for epidural labor analgesia, based on its positive effects on neonatal outcomes and parturients. ${ }^{16,17}$ In addition, sufentanil minimizes motor block when combined with ropivacaine. ${ }^{5-7}$

In a double-blind study ${ }^{18}$ on pregnant women who were administered ropivacaine or levobupivacaine for epidural labor analgesia, the minimum local analgesic concentration (MLAC) for ropivacaine was found to be $0.092 \%$ (95\% CI, $0.082-0.102 \%$ ) using the Dixon and Massey formula. This
MLAC value was consistent with that seen in our control group. In another study using up-down sequential allocation, Boulier et $\mathrm{al}^{5}$ found that in combination with sufentanil $(0.5$ $\mu \mathrm{g} / \mathrm{mL}$ ), the MLACs for epidural ropivacaine and levobupivacaine were $0.023 \% \mathrm{w} / \mathrm{vol}(95 \% \mathrm{CI}, 0.005-0.041)$ and $0.020 \% \mathrm{w} / \mathrm{vol} \quad(95 \%$ CI, $0.008-0.032)$, respectively. However, this study included patients with cervical dilation of $3-7 \mathrm{~cm}$, and $20 \mathrm{~mL}$ of the analgesic was used initially. Based on the EC50 values for ropivacaine in our present study, it appears that the inclusion criteria, mode of administration, and ethnic differences could influence the optimal ropivacaine dose. Women carrying the p.118A/G variant allele for the OPRM1 gene have been shown to require a lower ED50 for epidural sufentanil. ${ }^{19}$ This suggests that polymorphism of the $\mu$-opioid receptor gene is also an indirect factor that affects the calculation of ropivacaine EC50.

Table I Demographic Characteristics of Enrolled Parturients (Mean \pm Standard Deviation)

\begin{tabular}{|l|c|c|c|c|}
\hline Characteristic & Group C $(\mathbf{n}=\mathbf{3 0})$ & Group S $(\mathbf{n}=\mathbf{3 0})$ & t-value & P-value \\
\hline Mean age $(\mathbf{y})$ & $27.27 \pm 3.58$ & $27.70 \pm 3.20$ & -0.494 & 0.623 \\
\hline Weight $(\mathrm{kg})$ & $67.20 \pm 7.62$ & $64.38 \pm 5.48$ & 1.644 & 0.106 \\
\hline Height $(\mathrm{cm})$ & $159.33 \pm 5.47$ & $158.37 \pm 4.44$ & 0.751 & 0.456 \\
\hline Body mass index $\left(\mathrm{kg} / \mathrm{m}^{2}\right)$ & $26.43 \pm 2.26$ & $25.69 \pm 2.24$ & 1.275 & 0.207 \\
\hline Gestational week & $39.40 \pm 0.85$ & $39.52 \pm 0.93$ & -0.497 & 0.621 \\
\hline
\end{tabular}


Table 2 Comparison of Labor Analgesia Related Adverse Reactions

\begin{tabular}{|l|c|c|c|c|}
\hline Index & Group C (n = 30) & Group S (n = 30) & $X^{\mathbf{2} \text { value }}$ & P-value \\
\hline Hypotension & 0 & 0 & & $/$ \\
\hline Respiratory depression & 0 & 0 & & $/$ \\
\hline Maternal bradycardia & 0 & 0 & 1.017 & 1.00 \\
\hline Itching & 0 & 2 & 0.351 & 0.554 \\
\hline Nausea & 1 & 1 & 0.00 & 1.00 \\
\hline Vomiting & 1 & 0 & & $/$ \\
\hline Urinary retention & 0 & 1 & & \\
\hline
\end{tabular}

Another study compared dexmedetomidine $(0.5 \mu \mathrm{g} / \mathrm{mL})$ with sufentanil $(0.5 \mu \mathrm{g} / \mathrm{mL})$ when administered in combination with high $(0.125 \%)$ or low $(0.08 \%)$ concentrations of ropivacaine. ${ }^{8}$ The high dose of ropivacaine with sufentanil achieved a better analgesic effect than the low dose of ropivacaine. Moreover, the higher dose did not increase the incidence of complications. A comparison of dexmedetomidine $(0.5 \mu \mathrm{g} /$
$\mathrm{mL})$ and sufentanil $(0.5 \mu \mathrm{g} / \mathrm{mL})$ as adjuvants in combination with $0.1 \%$ ropivacaine showed that the former resulted in a better analgesic effect and shorter first labor stage duration. ${ }^{7}$ However, this study had no in-depth analysis of the cross effect of sufentanil with ropivacaine.

Cai et al determined the EC50s of sufentanil and ropivacaine separately. ${ }^{20}$ The EC50 of epidural ropivacaine

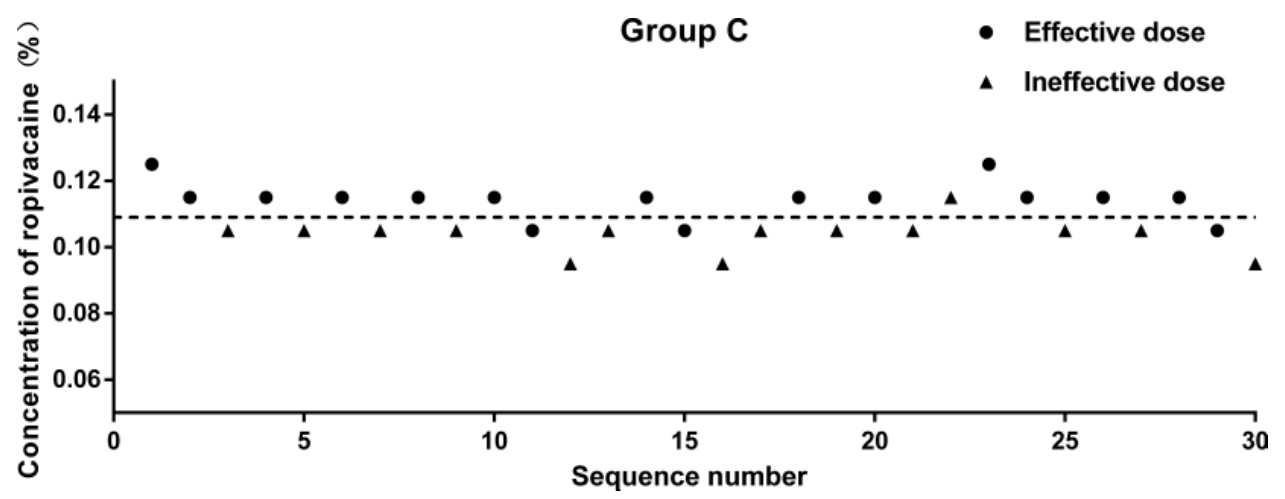

Figure $\mathbf{2}$ Stepwise dose adjustment of ropivacaine for epidural labor analgesia using up-and-down method. "•" indicate an effective dose, and " $\mathbf{\Delta}$ " indicate an ineffective dose.

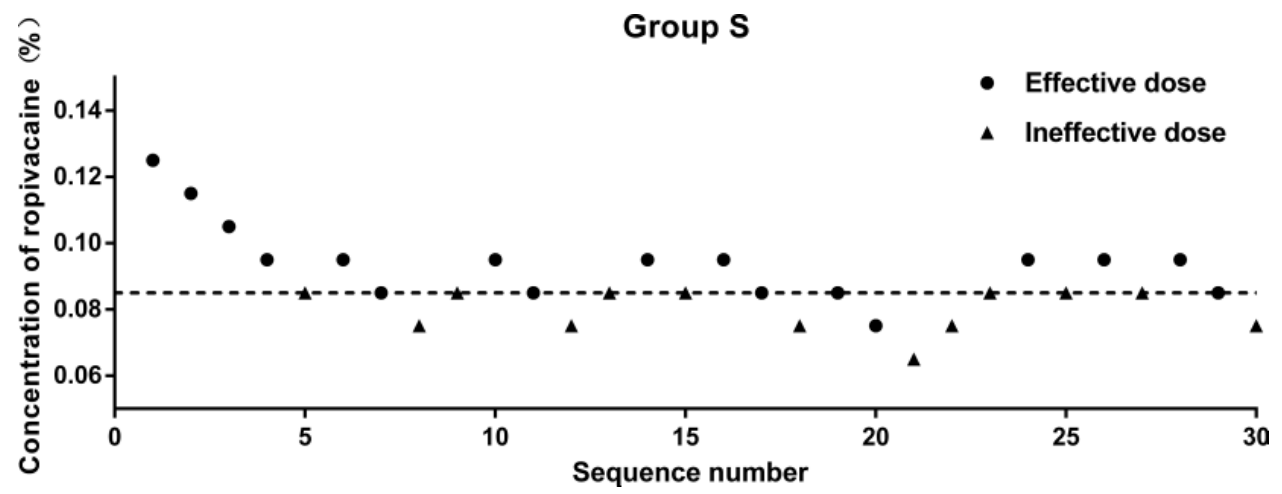

Figure 3 Stepwise dosage adjustment of epidural ropivacaine for labor analgesia combined with sufentanil. "•" indicate an effective dose, and “ $\mathbf{\Delta}$ ” indicate an ineffective dose. 
Table 3 Comparison of the Duration of Labor, Neonatal Apgar Score and Umbilical Artery pH (Mean \pm Standard Deviation)

\begin{tabular}{|c|c|c|c|c|}
\hline & Group $C(n=30)$ & Group $S(n=30)$ & t-value & P-value \\
\hline Onset of analgesia (minutes) & $13.10 \pm 1.91$ & $12.90 \pm 1.95$ & 0.401 & 0.690 \\
\hline Duration of first stage (minutes) & $386.0 \pm 96.0$ & $367.8 \pm 66.7$ & 0.855 & 0.396 \\
\hline Duration of second stage (minutes) & $38.56 \pm 9.07$ & $37.20 \pm 5.72$ & 0.698 & 0.488 \\
\hline I-minute Apgar score & $9.97 \pm 0.18$ & $9.97 \pm 0.18$ & 0.000 & 1.000 \\
\hline 5-minute Apgar score & All 10 & All 10 & 0.000 & 1.000 \\
\hline 10-minute Apgar score & All 10 & All 10 & 0.000 & 1.000 \\
\hline Umbilical artery $\mathrm{pH}$ & $7.24 \pm 0.099$ & $7.23 \pm 0.083$ & 0.410 & 0.683 \\
\hline Umbilical artery $\mathrm{PaO}_{2}(\mathrm{mmHg})$ & $19.87 \pm 6.96$ & $22.77 \pm 6.99$ & -1.610 & 0.113 \\
\hline Umbilical artery $\mathrm{PaCO}_{2}(\mathrm{mmHg})$ & $52.17 \pm 13.78$ & $50.07 \pm 10.89$ & 0.655 & 0.515 \\
\hline Parturient self-control degree & $7.43 \pm 0.57$ & $8.33 \pm 0.71$ & -5.581 & 0.000 \\
\hline Parturient satisfaction & $7.53 \pm 0.57$ & $8.28 \pm 0.74$ & -4.397 & 0.000 \\
\hline
\end{tabular}

combined with $0.3 \mu \mathrm{g} / \mathrm{mL}$ sufentanil was $0.09687 \%(95 \%$ CI, $0.08944-0.1043 \%$ ), while that for epidural sufentanil when co-administered with $0.1 \%$ ropivacaine was $18.76 \mu \mathrm{g}$ (95\% CI 13.5-24.48). The EC50 calculated in our study $(0.085 \%)$ was lower because sufentanil was administered at relatively higher concentrations.

Epidural co-administration of $0.15 \%$ ropivacaine and $0.5 \mu \mathrm{g} / \mathrm{mL}$ sufentanil for pain control after cesarean section exhibited lower numerical rating scale (NRS) scores and higher patient-satisfaction scores. ${ }^{21}$ In this study, the sufentanil and ropivacaine combination resulted in a higher degree of parturient self-motor control and pain relief, but not absolute satisfaction. Notably, the Apgar scores at 5 and 10 mins were 10 for almost all neonates. The two groups showed no significant difference in the maternal and fetal side effects, consistent with previous findings. ${ }^{7}$

The limitations of the current study include: (1) the test dose of lidocaine may have impacted the initial analgesia quality, and (2) the side effect comparison is not robust enough since the up-down study is not specifically designed for it. Thus, large studies are needed to evaluate individual differences in pain perception.

\section{Conclusions}

Epidural sufentanil $(0.5 \mu \mathrm{g} / \mathrm{mL})$ combined with ropivacaine reduced the EC50 of ropivacaine by $22 \%$ for labor analgesia in healthy term pregnancy.

\section{Data Sharing Statement}

The individual participant's data underlying published results reported in this study can be accessed with approval from the corresponding authors after publication. The study protocol, statistical analysis plan, and clinical study report will also be available.

\section{Acknowledgments}

The authors would like to thank Professor Youchang Li (Chongqing health Center for Women and Children) for the supervision of clinical performs and assistance. This study was supported by Institutional Research Grants of Chongqing Health Center for Women and Children (No. 2019YJMS02).

\section{Disclosure}

The authors report no conflicts of interest in this work.

\section{References}

1. Juang J, Gabriel RA, Dutton RP, Palanisamy A, Urman RD. Choice of anesthesia for cesarean delivery: an analysis of the national anesthesia clinical outcomes registry. Anesth Analg. 2017;124(6):1914-1917. doi:10.1213/ANE.0000000000001677

2. American College of Obstetricians and Gynecologists. ACOG practice bulletin no. 209: obstetric analgesia and anesthesia. Obstet Gynecol. 2019;133(3):e208-e225. doi:10.1097/AOG.0000000000003132

3. Mitra S, Arora J, Ahuja V, Takkar N. Combined spinal-epidural for labor analgesia with low-dose bupi- vacaine but without any opioid in the spinal component: can we improve upon the traditional? Acta Anaesthesiol Belg. 2015;66(4):9-15.

4. Nakamura G, Ganem EM, Rugolo LM, Castiglia YM. Effects on mother and fetus of epidural and combined spinal-epidural techniques for labor analgesia. Rev Assoc Med Bras (1992). 2009;55(4):405-409. doi:10.1590/S0104-42302009000400014 
5. Boulier V, Gomis P, Lautner C, Visseaux H, Palot M, Malinovsky JM. Minimum local analgesic concentrations of ropivacaine and levobupivacaine with sufentanil for epidural analgesia in labour. Int J Obstet Anesth. 2009;18(3):226-230. doi:10.1016/j. ijoa.2009.02.002

6. Buyse I, Stockman W, Columb M, Vandermeersch E, Van de Velde M. Effect of sufentanil on minimum local analgesic concentrations of epidural bupivacaine, ropivacaine and levobupivacaine in nullipara in early labour. Int J Obstet Anesth. 2007;16(1):22-28. doi:10.1016/j.ijoa.2006.07.008

7. Zhang T, Yu Y, Zhang W, Zhu J. Comparison of dexmedetomidine and sufentanil as adjuvants to local anesthetic for epidural labor analgesia: a randomized controlled trial. Drug Des Devel Ther. 2019;13:1171-1175. doi:10.2147/DDDT.S197431

8. Cheng Q, Bi X, Zhang W, Lu Y, Tian H. Dexmedetomidine versus sufentanil with high- or low-concentration ropivacaine for labor epidural analgesia: a randomized trial. J Obstet Gynaecol Res. 2019;45(11):2193-2201. doi:10.1111/jog.14104

9. Dixon WJ. Staircase bioassay: the up-and-down method. Neurosci Biobehav Rev. 1991;15(1):47-50. doi:10.1016/S0149-7634(05) 80090-9

10. Xiao F, Wei $\mathrm{C}$, Chang $\mathrm{X}$, et al. A prospective, randomized, double-blinded study of the effect of intravenous ondansetron on the effective dose in $50 \%$ of subjects of prophylactic phenylephrine infusions for preventing spinal anesthesia-induced hypotension during cesarean delivery. Anesth Analg. 2020;131(2):564-569. doi:10.1213/ANE.0000000000004534

11. Liu L, Drzymalski D, Xu W, Zhang W, Wang L, Xiao F. Dose dependent reduction in median effective concentration (EC50) of ropivacaine with adjuvant dexmedetomidine in labor epidural analgesia: an up-down sequential allocation study. $J$ Clin Anesth. 2021;68:110115. doi:10.1016/j.jclinane.2020.110115

12. Yentis SM, Lucas DN, Brigante L, et al. Safety guideline: neurological monitoring associated with obstetric neuraxial block 2020: a joint guideline by the Association of Anaesthetists and the Obstetric Anaesthetists' Association. Anaesthesia. 2020;75 (7):913-919. doi:10.1111/anae.14993
13. Patel NP, El-Wahab N, Fernando R, et al. Fetal effects of combined spinal-epidural vs epidural labour analgesia: a prospective, randomised double-blind study. Anaesthesia. 2014;69(5):458-467. doi:10.1111/anae. 12602

14. Pace NL, Stylianou MP, Warltier DC. Advances in and limitations of up-and-down methodology: a precis of clinical use, study design, and dose estimation in anesthesia research. Anesthesiology. 2007;107 (1):144-152. doi:10.1097/01.anes.0000267514.42592.2a

15. Payton ME, Greenstone MH, Schenker N. Overlapping confidence intervals or standard error intervals: what do they mean in terms of statistical significance? J Insect Sci. 2003;3:34. doi:10.1673/ 031.003 .3401

16. Amer-Wahlin I, Christoffersson M, Dahlgren N, Rydhstroem H. Epidural analgesia with sufentanil during labor and operative delivery. Acta Obstet Gynecol Scand. 2000;79(7):538-542.

17. Wang Y, Xu M. Comparison of ropivacaine combined with sufentanil for epidural anesthesia and spinal-epidural anesthesia in labor analgesia. BMC Anesthesiol. 2020;20(1):1. doi:10.1186/s12871-0190855-y

18. Benhamou D, Ghosh C, Mercier FJ. A randomized sequential allocation study to determine the minimum effective analgesic concentration of levobupivacaine and ropivacaine in patients receiving epidural analgesia for labor. Anesthesiology. 2003;99(6):1383-1386. doi:10.1097/00000542-200312000-00022

19. Camorcia M, Capogna G, Stirparo S, Berritta C, Blouin JL, Landau R. Effect of mu-opioid receptor A118G polymorphism on the ED50 of epidural sufentanil for labor analgesia. Int J Obstet Anesth. 2012;21(1):40-44. doi:10.1016/j.ijoa.2011.10.001

20. Cai S, Zheng J, Meng Q, et al. Investigation of the minimum local analgesic concentration of epidural sufentanil combined with ropivacaine for labor analgesia. Clin Ther. 2020;42(1):210-219. doi:10.1016/j.clinthera.2019.10.011

21. Miao F, Feng K, Feng X, et al. The analgesic effect of different concentrations of epidural ropivacaine alone or combined with sufentanil in patients after cesarean section. Front Pharmacol. 2021;12:631897. doi:10.3389/fphar.2021.631897

\section{Publish your work in this journal}

Drug Design, Development and Therapy is an international, peerreviewed open-access journal that spans the spectrum of drug design and development through to clinical applications. Clinical outcomes, patient safety, and programs for the development and effective, safe, and sustained use of medicines are a feature of the journal, which has also been accepted for indexing on PubMed Central. The manuscript management system is completely online and includes a very quick and fair peer-review system, which is all easy to use. Visit http://www. dovepress.com/testimonials.php to read real quotes from published authors. 